Send your letters to the editor, British Dental Journal, 64 Wimpole Street, London W1G 8YS E-mailbdj@bda.org

Priority will be given to letters less than 500 words long. Authors must sign the letter, which may be edited for reasons of space.

\section{Contract daydream}

Sir, I am 64 years old and have been managing two part time single handed practices for 15 years. I closed one practice just before the new contract came into existence hoping to find part time work elsewhere. I have been applying everywhere and getting the reply that there are no funds for expansion and also no patients. In three practices in which I work, I am reduced to working half a day in each.

The patients are told that only one item of treatment can be done for one band of charge. Children and exempt patients are also turned away if they are unable to pay. I believe that in the not very distant future we will see a marked deterioration of oral health among the less well off population, many thriving dental practices will struggle and there will also be loss of goodwill between dentists and patients. The success of this dental contract is all but in the imagination of the chief dental officer and his paymasters.

I. A. S. Syed doi: 10.1038/sj.bdj.4814049

\section{A financial vacuum}

Sir, I read with interest the first instalment of what promises to be an interesting and useful series (BDJ 2006; 200: 661-665). In this first paper the authors have put forward a coherent, well supported and persuasive argument for the biological and clinical benefits of the provision of implants over conventional treatment strategies.

The concern I wished to raise, however, relates to the omission of an important component from the authors' discussion; namely economics. At no point in this paper are the cost implications discussed. I do not doubt the authors' argument that implants provide a better solution. The problem is that there is no mention that for many, these benefits may be financially unobtainable.

I do not suggest that the paper 'degenerate' into a NICE cost/benefit analysis, but where a significant change in clinical practice is being advocated a mention would seem sensible.
A defence union (or more importantly the GDC) would not consider valid consent to have been obtained for a treatment strategy without a discussion and estimate of the cost. I understand that many authors work in a secondary or tertiary care environment where patients may not contribute financially toward the cost of their treatment, or treat patients already self selected to be able to pay (on referral in specialist private practice). But this does not exonerate them discussing the financial implications of their clinical recommendations on the rest of us. Articles published in the $B D J$ are after all, mainly read by those working in primary care, dealing with patients for whom this is a very real concern

Indeed the most regularly cited barriers to dental care by patients are access, anxiety, fear of pain and cost. I seem to recall that the patient consultation documents published prior to the Government's recent changes contained many responses criticising the cost of NHS fees even for exams and identifying them as a significant barrier to care. I think that the treatment being advocated here may be a bit more expensive than that!

Where expert opinion advocates a change in clinical practice, whether it concerns the viability of routine use of implants, the single use of endodontic files or another issue, experts have a responsibility not to do so in a financial vacuum.

Primary care does not expect the secondary and tertiary sectors to have all the answers, except on clinical issues that is (only joking), though it would be nice. We tend to be realistic. But it would be likely to facilitate a reduction in potential resistance to change if the side putting forward the idea identified problems with its implementation. This can only result in a more informed discussion from all parties and the correct identification of barriers to change at an earlier stage of the process.

I look forward to the next article with interest.

\section{M. Smith}

Cumbria

doi: 10.1038/sj.bdj.4814050

\section{Cinnamaldehyde}

Sir, I recently examined a patient with a quite severe stomatitis involving the tongue and buccal mucosa. It resolved speedily when the patient discontinued the use of 'Spicy Sensodyne toothpaste'. It would appear that the causative factor was Cinnamaldehyde. PubMed/Medline reveals several papers in the American and dermatology literature.

Unfortunately, though not unreasonably, the patient declined to recommence usage of the toothpaste in order to confirm the link.

I have not come across this association before and wondered whether colleagues have had this experience.

If so, then perhaps there should be wider knowledge of a connection between Cinnamaldehyde and stomatitis. Hence my letter.

B. Littler

Chelmsford

doi: 10.1038/sj.bdj.4814051

\section{Pure gimmickry}

Sir, I would like to register my (environmental) dismay at oral hygiene products such as power toothbrushes.

I received one of these as a freebie and started it up to see what it was all about. When you do there is plenty of movement of the yellow blades and some bristle movement. However, as soon as you touch the blades and bristles gently onto your finger all movement stops and there is, as far as I can see, no discernable power transfer at all. Any tooth cleaning properties will be due to the power input from the arm of the person using it. It looks like pure gimmickry to me.

The point I would like to make is that there is a huge amount of precious resources going into making these things (wires, plastics and a battery, of all things), all of which we can ill afford to waste.

These huge corporations really should stop going after the profits in such a blatantly wasteful way and start looking at what is going to be the really cool stuff like biodegradable plastics for their products (such as the type used to make the new biodegradable bottles). There are so many people out there who would rather buy a 
biodegradable toothbrush that it must be worth developing one.

Needless to say I look at this type of product and recommend that my patients avoid them both on environmental grounds and whether or not they actually work for the patient's oral health (or just for a company's profits).

For the sake of our planet, let's ignore this type of product and stick to what works. The corporations will soon get the message if no-one buys the things.

\section{J. Rigby}

By email

doi: 10.1038/sj.bdj.4814052

\section{Resolving complaints}

Sir, a quick and effective service for resolving complaints about private dental care now exists, as requested in a letter to the editor in the $B D J(2006 ; 201: 66)$.

The Dental Complaints Service, which is independent of the General Dental Council and its Fitness to Practise procedures, aims to resolve complaints as fairly, efficiently, transparently and quickly as possible.

The thrust of the new service is to help dental professionals and patients to restore their relationship. Initially, we guide complainants to their practices' own complaints procedures. If a practice can't resolve a complaint, our advisers attempt to resolve it informally. More intractable complaints may go to a regional panel of trained volunteers, lay and dental professional.

Since our launch on 24 May we have already dealt with more than 2,500 enquiries from patients and members of the dental team, relating to over 400 complaints: with the help of dental practices all but a dozen remain outstanding and we're continuing to discuss with the practice and patient how best to resolve them. We have held only two panels, one in Bournemouth and one in Croydon, because most complaints are resolved much earlier in the process.

We hope that our new service will be beneficial to patient, dental professional and practice, encouraging the continued journey of care of the patient at their existing practice.

For more information, contact the Dental Complaints Service on its helpline, which is 08456120540 (local rate), or visit our website www.dentalcomplaints.org.uk, oremailinfo@dentalcomplaints.org.uk.

\section{G. Miles}

Croydon

doi: 10.1038/sj.bdj.4814053

\section{Fruit for ulcers}

Sir, among common oral mucosal findings, ulcerations of a recurring history are reported frequently. These ulcers have been diagnosed as Recurrent Aphthous Ulceration (RAU). On many occasions, due to increased recurrence, patients find their own ways of overcoming the symptoms, often resorting to bizarre remedies. This can range from chewing on plant leaves to consuming multivitamin tablets. As the ulcers can last for 7-10 days, by the time they clear up, it is difficult to say whether the treatment itself actually worked or whether the ulcer healed on its own. Having gone through the earlier works on RAU, I thought further research into its management was necessary, in particular the investigation of an old herbal remedy.

A relative of mine mentioned to me that he obtained relief from RAU by using jeera fruits (Cumin - Cuminum cyminum). He was also using jeera grains for a digestive problem and constipation. This remedy provided relief for all of his ailments, and was a complete cure for his RAU.

I have since discovered that this simple, non-harmful remedy has widespread popularity. People suffering from RAU for many years have been able to get complete relief. Patients were asked to chew on the raw fruits (grains) of jeera, 8-10 fruits, and swallow, three times a day. Over a period of 1-3 months' duration, the severity of the symptoms, duration of ulcers, frequency of recurrence, number and size of ulcers reduced in that order, and the patients reported complete relief from this once frequent problem. The exact mechanism of the action of jeera fruits in bringing about this dramatic relief is yet to be explored and understood. Whatever the mode of action, the patients have been relieved of their complaint and no adverse effects have been reported. In fact, jeera (cumin) is an essential component of the daily diet in the Indian subcontinent. Does the use of cumin help in improving the immunity of the individual? Does this render the oral epithelium more keratinised? (In smokers having a history of RAU, ulcers are known to recur once they quit smoking. Smoking is assumed to make the oral epithelium more keratinised.) Is it because cumin is known to relieve constipation? It thereby cures RAU since constipation is said to be one of the causes for oral ulceration. More cases may have to be treated and evaluated to arrive at a definite conclusion for universal acceptance of this miracle drug. Despite the low number of cases that have been successfully treated so far - to my knowledge - I am certainly encouraged to explore this further.

K. Mahalinga Bhat

Manipal

doi: 10.1038/sj.bdj.4814054 


\section{Unwanted effects}

Sir, we were interested to read B. Arends' letter (BDJ 2006; 201: 66-67) concerning the effects of dental materials on the quality of MRI scans.

In our departmental journal club, we recently looked at the question 'Should fixed orthodontic appliances be removed prior to MRI scans?' This clinical scenario was prompted by a request from an intensive care nurse for a member of the department to attend to remove the fixed orthodontic appliance of a patient about to undergo an emergency MRI scan of the brain.

We actually found quite a lot of information on the subject of the effects of dental materials on MRI scans by carrying out a focussed search through Medline, using the keywords: orthodontics, orthodontic wires, orthodontic brackets, dental materials, implants, safety, artefacts and Magnetic Resonance Imaging.

The potential unwanted effects caused by the interaction of MRI and dental materials fall into three broad groups: mechanical - for instance where an external strong magnetic field may dislodge or move a ferromagnetic material into a position parallel to the lines of that field; physical - for instance where a material is heated up due to the high frequency electromagnetic field; and artefactual - where the accuracy of the scan image is affected by a material.

Although there are several sources of evidence in relation to dental materials and the creation of artefacts, we found it to be conflicting. Furthermore, alloys may well behave very differently from 'pure' metals, but manufacturers are often reluctant to disclose the composition of their 'trademark' alloys. What was apparent, however, was that if a material was capable of causing an artefact on a scan, it could do so on a 'slice' of the scan several sections distant from that containing the material. An example is a $25 \mathrm{~mm}$ artefact/distortion around a steel implant in a pig-jaw experiment. ${ }^{1}$ The ability to cause an artefact seems to depend on the magnetic properties of the metal object as well as its shape, size, space orientation and homogeneity of the alloy.

From the point of view of our 'orthodontic appliance and MRI scan' question we concluded from the available evidence that:

- Fixed orthodontic appliances are safe for use in MRI scanners so long as they are firmly bonded and carefully ligated

- Steel retainer bonds should be checked prior to scan to ensure their attachment

- It is better to leave a non-ferromagnetic wire in place, as this will keep the brackets together even if the enamel bond fails
- If the dento-alveolar region is the study, the plane of the scan should be altered to avoid the site of metal devices

- Orthodontic brackets and wires should be removed to prevent artefacts if this is not possible

- There should be no need to remove a firmly bonded and carefully ligated fixed orthodontic appliance prior to an MRI scan of the brain.

\author{
B. Cross \\ H. Beckett \\ Portsmouth \\ 1. Eggers $G$, Rieker $M$, Kress B et al. Artefacts in \\ magnetic resonance imaging caused by dental \\ material. Magma 2005; 18: 103-111.
}

doi: 10.1038/sj.bdj.4814055

\section{BDA for DCPs}

Sir, when DCPs start to register with the GDC on 31 July 2006, will they also be allowed to join the British Dental Association (BDA)? There are many of us who would like our GDC recognition to be carried over to the BDA, and this would be a start.

R. Prior

By email

The Chief Executive of the BDA, Peter Ward, responds: this is a highly significant time for the development of the dental team, with new opportunities opening up for dental care professionals. This focus on the contribution of the whole dental team is welcomed and supported by the BDA; whether or not this support will involve extending membership in the future, will be up to our existing members to decide.

doi: 10.1038/sj.bdj.4814056

\section{New power}

Sir, regular readers of your columns may recall some correspondence in 2000 (BDJ 2000; 188: 231, 416) relating to GDC policy and the potential recovery of costs in conduct cases. The then Chief Executive and Registrar made the point that the GDC was not empowered under the 1984 Dentists Act to recover its costs in conduct cases and that the Council was not seeking to recover such costs accepting that professional self-regulation confers a responsibility on all dentists to meet the costs of maintaining professional standards.

At the time I observed in your pages, inter alia, that the prospect of the GDC having a financial interest in the outcome of the disciplinary proceedings being dealt with by its Committees was an extremely unhappy one. 
In case it may just have escaped some of your readers' attention, buried deeply within new legislation which has recently come into force, is ... a power enabling Committees of the GDC to make such Orders as to costs as they think fit (Schedule 3, paragraph 6 of the Dentists Act 1984 as amended)!

It seems that six years is a very long time in dental politics.

C. D. N. Morris

Solicitor

London

doi: 10.1038/sj.bdj.4814057

\section{Learn from America}

Sir, I read S. Edwards letter: Fear of litigation (BDJ 2006; 201: 133) with interest and a great deal of sympathy.

To comply with an ever increasing number of rules and regulations being imposed on us is difficult when one is compromising between professional life, social life and what little is left of family life. There are also the constraints of a shrinking income. Our American cousins started with the pressures of litigation in the 1960s and at that time went through the same feeling of fear as we feel currently. They are well and truly used to it by now. I feel that we have got to look at litigation like any other dispute for which a law court may act to judge and as one may well look at judgement as the result of debate between lawyers. To lose a case when one feels strongly about one's innocence is of course very upsetting but the sooner we accept it, the sooner we can get on with our lives. We should learn from the Americans in this matter and not give up working.

I. A. S. Syed

By email

doi: 10.1038/sj.bdj.4814058

\section{Jig relief}

Sir, as a member of the British Society for the Study of Occlusion (www.bsos. org.uk) I was interested to read the case study on Temporalis Hypertrophy by S. Rokadiya and N. J. Malden (BDJ 2006; 201: 153-155). Perhaps as a mere GDP with an interest in TMD and occlusion I am missing something, but the facts that the lady claimed to 'bang her teeth together', was in 'a stressful period in her life' and showed painful hypertrophy in one of her muscles of mastication, would seem to point to a very obvious cause and effect? The fabrication of a Lucia Jig anterior deprogrammer would be an easy, non-invasive and inexpensive way to test this hypothesis as if this gave relief to her symptoms it would point to an occlusal cause for them. The Michigan splint provided later in this lady's treatment provided 'almost immediate reduction in pain as well as reduction in the prominence of her temporalis muscles.' The article does not say if this splint was fabricated using a face bow and leaf gauge deprogrammer and if the appliance was adjusted to centric relation so as to give correct posterior discussion in function and readjusted over time as the muscle spasm subsided. Nor does it say for how long it was worn, each day or in total.

I have seen many times with my own patients that their symptoms can be relieved by regularly wearing a Jig or correctly adjusted appliance, leading to final equilibration of their teeth, which is a much less expensive and invasive option than embarking on extensive investigations and treatment modalities such as CT scans, long term medication or surgery. Obviously if the symptoms are not relieved by the provision of a Lucia Jig then further investigation can be carried out to ascertain the cause of their symptoms. I would urge anyone who is interested in gaining a greater insight into treating such cases to attend the courses run by IPSO (International Partnership

for the Study of Occlusion) via www.stockportdentalseminars.com.

\section{P. Mandon-Gassman}

Canterbury

doi: 10.1038/sj.bdj.4814059

\section{Gaps in the curriculum}

Sir, having recently permitted a pleasant 15-year-old girl to observe me on work experience, while I frantically attempt to accumulate UDAs in general practice, I asked her what I thought would be a simple question - 'What is the hard outer shell of a tooth called?'

Alas, the answer of enamel was not forthcoming. So I asked my 40-year-old taxi driver patient if he knew - also no idea. Then I asked my recently appointed 17-year-old dental nurse if there was any hope of salvaging the situation, and rejoice she remembered. Unfortunately this was only because I had to tell her when she first started over a month ago. They had never even heard of dentine or pulp.

The work experience student hastened to add that she had never been taught tooth structure in school, and neither had my dental nurse. She also told me she could name every component of a blast furnace without a second's breath. I have a vague memory of when I was about eight or nine years old of being shown a diagram of a tooth in science class.

Surely this issue raises an obvious question - why doesn't this get taught in schools? It saddens me that a bright girl from a good home, who goes to a respected comprehensive school in Cardiff, had no idea about teeth despite saying she wants to be a dentist. Surely there is no hope for children from a more deprived background? Isn't it obvious that this is where oral health education and promotion should start - by actually teaching our kids in schools the fundamentals about teeth, therefore helping them understand the causes of tooth decay? At least this country will never have a problem producing steel, and it shows taxi drivers don't know everything.

T. D. Phillips

Cardiff

doi: 10.1038/sj.bdj.4814060

\section{Prescribing patterns}

Sir, the recent confusion surrounding the new guidelines for antibiotic prophylaxis has highlighted the need for clarity on this important subject and hopefully the eventual publication of a NICE guideline will achieve this. I recently conducted a study on the prescription of antibiotic prophylaxis by GDPs and CDS dentists in Barking, Dagenham and Havering which demonstrated both wide variation in prescribing practice, and this need for clarity.

In total, 304 questionnaires were distributed and only $22.4 \%$ were returned making it difficult to draw accurate conclusions from the study. This was disappointing given the importance of this subject and the recent controversy surrounding it. The dentists who did reply relied mainly on the BNF guidelines, but a significant number used alternative guidelines, especially those of the Royal College of Surgeons/British Cardiac Society. Inevitably, when different guidelines are used, differences in practice emerge. However, it was found that among those who responded, inappropriate prescription was widespread, especially in terms of the cardiac conditions cover was prescribed for (including a functional heart murmur and rheumatic fever without any rheumatic heart disease). It was also found that the dentists would welcome further training on this subject.

Whilst the low response rate makes it difficult to infer anything about more widespread general practice, I think it is reasonable to assume that these prescribing patterns are likely to be repeated across the country and will continue to be until there is a consensus from the experts and appropriate training for dentists of all levels of experience.

D. Jones

By email

doi: $10.1038 /$ sj.bdj.4814061 